\title{
P53/MDM2 CO-EXPRESSION CORRELATES WITH THE TUMOUR DIFFERENTIATION IN ORAL SQUAMOUS CELL CARCINOMA - A RETROSPECTIVE STUDY AND A SYSTEMATIC REVIEW
}

Y.F. Choon, A. Ramanathan, H. Ali, W.M.N. Ghani, S.C. Cheong, R.B. Zain. P53/MDM2 co-expression correlates with the tumour differentiation in oral squamous cell carcinoma $-A$ retrospective study and a systematic review. Annal Dent Univ Malaya 2011; 18: $8-17$.

\section{ABSTRACT}

Background: $\mathrm{MDM} 2$ and $\mathrm{p} 53$ are involved in a negative feedback loop where p53 regulates MDM2 at the transcriptional level. MDM2, in turn, downregulates $\mathrm{p} 53$. This co-ordinated interaction between these proteins is set to play an important role in the regulation of cell cycle progression following DNA damage to cells. The over-expression of both p53 and MDM2 has been reported in various cancers. However there are only few studies discussing the co-expression of MDM2 with p53 in oral squamous cell carcinoma

Aim: The purpose of this study was to determine the correlation of co-expression of p53, MDM2, and $\mathrm{Ki}-67$ proteins with clinico-pathological factors in oral squamous cell carcinoma (OSCC) and to conduct a systematic review of the co-expression of p53/MDM2.

Method: This is a retrospective descriptive study and a systematic review. Formalin-fixed paraffinembedded tissues from 45 OSCC cases were stained by immunohistochemistry (IHC) for p53, MDM2, and Ki-67 proteins.

Results: Immuno-reactivity for $\mathrm{p} 53, \mathrm{MDM} 2$, and Ki-67 was seen in $75.6 \%, 97.8 \%$, and $62.2 \%$ cases of OSCC respectively. The co-expression of p53 and MDM2 (p53/MDM2) was detected in 97.1\%, however there was no significant correlation between p53 and MDM2 expression. Notably, p53/MDM2 coexpression was significantly associated with tumour differentiation ( $p$-value $=0.045$ ). The Ki-67LI was not significantly associated with neither MDM2 nor p53/MDM2 co-expression ( $p$-value $=0.268,0.916$ respectively).

Conclusion: The expression of MDM2 was not significantly associated with p53 expression suggesting that MDM2 expression is mediated by p53-independent pathways or mutated p53 could not induce the expression of MDM2 in this set of OSCCs. The only clinico-pathological parameter that correlates significantly with co-expression of p53/MDM2 is tumour differentiation where it is suggestive that the co-expression of these 2 proteins is indicative of aggressive tumour behavior.

Key words: Oral squamous cell carcinoma, MDM2, p53, Ki-67, immunohistochemistry, systematic review
Original Article

\begin{tabular}{l} 
Y.F. Choon ${ }^{1}$, A. Ramanathan ${ }^{1,2}, \mathrm{H} . \mathrm{Ali}^{2}$, \\
W.M.N. Ghani ${ }^{2}, \mathrm{~S} . \mathrm{C}$. Cheong $^{3,4}, \mathrm{R} . \mathrm{B}$. Zain $^{1,2}$ \\
\\
${ }^{1}$ Department of Oral Pathology, Oral Medicine \\
and Periodontology \\
${ }^{2}$ Oral Cancer Research and Coordinating Centre \\
${ }^{3}$ Department of Oral and Maxillofacial Surgery \\
Faculty of Dentistry, University of Malaya, \\
50603 Kuala Lumpur, Malaysia. \\
Tel No (Office): $+603-79674801$ \\
Email: yfchoon@um.edu.my \\
${ }^{4}$ Oral Cancer Research Team, Cancer Research \\
Initiatives Foundation (CARIF) \\
Sime Darby Medical Centre, \\
47500, Subang Jaya, Malaysia. \\
Corresponding author: Dr. Choon Yee Fan \\
\hline
\end{tabular}

\section{INTRODUCTION}

The National Cancer Registry (NCR 2006) in Peninsula Malaysia recorded oral cancers separately into three different segments that include the lip, mouth and tongue cancers. Among the males, tongue and mouth cancers were ranked $21^{\text {st }}$ and $26^{\text {th }}$ while among the females they were ranked $25^{\text {th }}$ and $19^{\text {th }}$ of all cancers respectively. However, when both mouth and tongue cancers were grouped together, cancer of the oral cavity made up about $1.8 \%$ of all cancers and was the $17^{\text {th }}$ most common cancers among males and $15^{\text {th }}$ most common cancers among the females (1).

p53 is a tumour suppressor gene (TSG) which plays a key role in the control of cell cycle, maintenance of genomic stability, cellular differentiation and apoptosis (2). In the case of DNA damage, p53 blocks cell cycle to allow for DNA repair (3). The expression of wild-type p53 protein is undetectable due to its short half-life. However, once mutated; its half-life increases and the protein can be detected by immunohistochemistry (IHC). Therefore, it was suggested that over-expression of p53 protein is indicative of the presence of $\mathrm{p} 53$ mutation (4).

The p53 protein can induce the transcription of the human homologue of murine double minute 2 oncogene (MDM2) (5). MDM2 and p53 are involved in a negative feedback loop where p53 regulates MDM2 at the transcriptional level $(5,6)$. MDM2, in turn, down-regulates p53. This co-ordinated interaction between these proteins is set to play an important role in regulation of cell cycle progression following DNA damage to cells $(6,7)$. MDM2 can binds to both wild- 
type and mutated p53 to form a complex, thus inhibiting the transcriptional activation function of $\mathrm{p} 53$ $(8,9)$. MDM2 inhibits wild-type p53-mediated G1 arrest and apoptosis $(10,11)$ and also plays a role in promoting $\mathrm{S}$ phase entry in the p53-independent pathway (12) thus driving cellular proliferation.

The over-expression of both p53 and MDM2 has been reported in various cancers such as melanomas (13), bladder cancer (14), osteosarcomas (15) and oral squamous cell carcinomas (OSCC) $(2,16-18)$.

Ki-67 antibody recognizes a cell nucleus antigen which is expressed maximally in the $\mathrm{G} 2$ and $M$ phases of cell cycle and thus reflects proliferation (19). Therefore $\mathrm{Ki}-67$ is used as a cellular proliferation marker.

Although there are many studies about p53 expression and OSCC, there are only few studies discussing the co-expression of MDM2 with p53 or Ki-67. Therefore, in this study, IHC was used to investigate the co-expression of p53 and MDM2 along with Ki-67 labelling index (Ki-67LI) in OSCC, and further evaluated the correlation between the overexpression of these proteins either individually or in combination, (p53/MDM2/Ki-67LI) with the demographic and clinico-pathological characteristics in OSCC patients.

Further, we conducted a systematic review of the English language literature to review all studies that have evaluated the correlation between the coexpression of p53/MDM2 with demographic and clinico-pathological characteristics in OSCC.

\section{MATERIALS AND METHODS}

\section{Samples:}

Forty-five formalin-fixed, paraffin embedded (FFPE) tissue samples were retrieved from the archives of the Department of Oral Pathology, Oral Medicine and Periodontology, Faculty of Dentistry, University of Malaya (UM). The demographic and clinicopathologic details for all cases were obtained from biopsy reports and the patients' clinical charts/folders. Ethical approval for this study was obtained from the Medical Ethics Committee, Faculty of Dentistry, UM [Medical Ethics Committee approval number: DFOP0301/0001(P)]. For all cases, hematoxylin and eosin stained slides were prepared and the diagnosis of OSCC was re-confirmed by two authors (RBZ and CYF).

\section{Immunohistochemistry:}

For each case, $4 \mu \mathrm{m}$ sections were cut from FFPE tissue blocks and dewaxed in xylene, rehydrated through alcohol and then treated with $3 \%$ hydrogen peroxide to block endogenous peroxidase activity. For antigen retrieval, the sections were soaked in $10 \mathrm{mM}$ citrate buffer (pH6) and processed in a microwave oven at $95^{\circ} \mathrm{C}$ for 20 minutes.
IHC was performed using the streptavidin-biotin complex method for p53 and Ki-67 whereas the En Vision ${ }^{\circledR}$ detection system was used for MDM2. The following primary antibodies were used: (1) p53 (clone DO-7, DAKO, 1:100 dilution for $45 \mathrm{~min}$ ), (2) MDM2 (Clone 1B10, Novacastra, 1:150 dilution for $30 \mathrm{~min}$ ) and (3) Ki-67 (clone MIB-1, DAKO, 1:100 dilution for $2 \mathrm{hrs}$ ).

OSCC tissues which were known to have overexpression of p53, MDM2 and Ki-67 were used as positive controls. Negative controls were performed by replacing the primary antibodies with Tris-buffered saline. The peroxidase reaction was developed using diaminobenzidine (DAB) as the chromogen and Herlich's hematoxylin was used for counter staining. The IHC staining was evaluated by two authors (RBZ and CYF) in 3 chosen fields at the invasive front for each case. A uniform scoring system was devised for positive nuclear/cytoplasm staining with p53 and MDM2 in the malignant epithelia as follows: $1+$ : $<20 \%$ of cells; $2+: 20-50 \%$; $3+:>50 \%$. The Ki-67LI was calculated using the ratio of Ki-67 positive nuclei to the total number of the cells in the 3 chosen fields and was expressed in percentage.

\section{Statistical Analysis:}

Statistical analysis of the data was carried out using SPSS version 12 to determine the correlation between demographic and clinico-pathologic parameters with the expression of p53, MDM2, Ki-67, either individually or in combination. Pearson's Chisquare and Fisher's exact were employed for data analysis of categorical data and Mann-Whitney U test was used for analyzing continuous data. A $p$-value of less than 0.05 is considered significant.

\section{Systematic Review:}

\section{Search Strategy:}

PubMed Medline and Elsevier Science Direct were systematically searched for relevant articles for the past 20 years from 1990 to 2010 by one of the authors (WN). The starting date of 1990 was chosen as the first suggestion that $M D M 2$ is an oncogene was reported in 1991 by Fakharzadeh and colleagues. The search strategy is as follows:

PubMed Medline:

1 - "Mouth Neoplasms" [Mesh] OR “oral cancer" OR "mouth cancer" OR "oral carcinoma" OR "oral malignancy" OR “oral tumor” OR “oral tumour” OR "oral squamous cell carcinoma"

2 - p53 OR Mdm2 OR MDM2 OR Ki67 OR Ki67LI OR P53

\section{$3-1$ AND 2}

Elsevier Science Direct:

"oral cancer" OR "mouth cancer" OR "oral carcinoma" OR “oral malignancy” OR “oral tumour” OR “oral 
squamous cell carcinoma" and p53 OR P53 OR MDM2 OR Mdm2 OR Ki67 OR Ki67LI.

\section{Inclusion criteria:}

The results from these searches were reviewed by title and abstract by 2 independent reviewers (AR and HA). Only the English language literature was included. The full manuscripts of appropriate studies were scrutinized and the studies were deemed "relevant" if they met the following inclusion criteria:

1. Samples used in the study were primary SCC of the oral cavity which were diagnosed histologically

2. Studies which assessed p53 and MDM2 (both markers) by IHC and compared the expression with demographic and clinico-pathologic parameters.

Exclusion criteria:

1. Other SCC of head and neck region such as oropharynx, larynx, recurrent SCC of the oral cavity and salivary gland tumours.

2. Studies which assessed p53 with molecular markers other than MDM2.

These inclusion and exclusion criteria were strictly adhered to allow a more meaningful systematic review.

\section{Data Extraction:}

Full-text published articles were obtained and reviewed by 2 independent reviewers (AR and HA). The data were extracted from these studies and collated in a Microsoft Excel worksheet. Clinical data such as age, gender, site and pathological data such as tumour size, lymph node metastasis, TNM staging, tumour grading and pattern of invasion were all recorded. Demographic data on ethnicity were recorded where available. IHC data were also recorded.

\section{RESULTS}

The demographic and clinico-pathologic details for 45 cases are presented in Table 1 . The details of tumour size, lymph node metastasis and TNM staging were available for only 35 cases (Table 1).

\section{p53 protein expression:}

The p53 immuno-positive OSCC cases mostly showed intense nuclear staining in tumour cells and were distributed along the basal and suprabasal layer at the tumour invasive front (Figure 1A). Thirty-four cases out of 45 cases $(75.6 \%)$ showed p53 positive immuno staining (Table 2) of which 5 cases (11.1\%), $8(17.8 \%)$ and $21(46.7 \%)$ with score $1+, 2+$ and $3+$ respectively. Eleven cases $(24.4 \%)$ were immunenegative for $\mathrm{p} 53$. The p53 expression does not

Table 1. Demographic and clinic-pathologic details of 45 OSCC cases

\begin{tabular}{|c|c|c|}
\hline & Category & $\begin{array}{c}\text { Number of patients } \\
\mathrm{n}(\%)\end{array}$ \\
\hline Age (Median=59 years old $)$ & $\begin{array}{l}<59 \text { years old } \\
\geq 59 \text { years old }\end{array}$ & $\begin{array}{l}22(48.9) \\
23(51.1)\end{array}$ \\
\hline Sex & $\begin{array}{l}\text { Male } \\
\text { Female }\end{array}$ & $\begin{array}{l}25(55.6) \\
20(44.4)\end{array}$ \\
\hline Race & $\begin{array}{l}\text { Indian } \\
\text { Non-Indiana }\end{array}$ & $\begin{array}{l}31(68.9) \\
14(31.1)\end{array}$ \\
\hline Site & $\begin{array}{l}\text { Buccal } \\
\text { Tongue } \\
\text { Lip } \\
\text { Others }\end{array}$ & $\begin{aligned} 19 & (42.2) \\
12 & (26.7) \\
3 & (6.7) \\
11 & (24.4)\end{aligned}$ \\
\hline Tumor size ${ }^{b}$ & $\begin{array}{l}\mathrm{T} 1 \text { and } \mathrm{T} 2 \\
\mathrm{~T} 3 \text { and } \mathrm{T} 4\end{array}$ & $\begin{array}{l}16(45.7) \\
19(54.3)\end{array}$ \\
\hline Lymph node metastasis ${ }^{b}$ & $\begin{array}{l}\text { No } \\
\text { N1 and N2 }\end{array}$ & $\begin{array}{l}15(42.9) \\
20(57.1)\end{array}$ \\
\hline TNM staging $^{b}$ & $\begin{array}{l}\mathrm{I} / \mathrm{II} \\
\mathrm{III} / \mathrm{IV}\end{array}$ & $\begin{array}{l}11(31.4) \\
24(68.6)\end{array}$ \\
\hline Broder's Grading & $\begin{array}{l}\text { Well differentiated (Group I) } \\
\text { Moderately differentiated (Group II) } \\
\text { Poorly differentiated (Group III) }\end{array}$ & $\begin{aligned} 19 & (42.2) \\
25 & (55.6) \\
1 & (2.2)\end{aligned}$ \\
\hline Pattern of invasion & $\begin{array}{l}\text { Cohesive (I and II) } \\
\text { Non-cohesive (III and IV) }\end{array}$ & $\begin{array}{l}14(31.1) \\
31(68.9)\end{array}$ \\
\hline
\end{tabular}

aNon-Indian - Chinese (10) and Malay (4)

bNumbers do not add up to the total due to missing data 
correlate significantly with any of the clinicopathologic characteristics.

\section{MDM2 protein expression:}

The immune-positivity of MDM2 was seen as intense nuclear staining in the basal and suprabasal layer at the tumour invasive front. The keratinized layer also showed intense nuclear staining (Figure 1B). MDM2 immuno-reactivity was seen in $44 / 45$ cases (97.8\%; Table 2) and all cases recorded a score of $3+$. MDM2 expression does not correlate with any of the clinico-pathologic parameters.

\section{Ki-67LI:}

The proliferating antigen MIB1 was detected in $28 / 45$ cases $(62.2 \%)$. The intensity of the staining ranged from highly intense to faint and was localized in the nuclei of the basal layer of the tumour islands and also the basal and suprabasal layers of the tumour epithelium at the invasive front (Figure 1C). The Ki-67LI ranged from $15.9 \%$ to $70.2 \%$ with a mean of $23.4 \% \pm$ SD 22.85 (median 19.4\%; data not shown). The Ki-67 expression does not correlate significantly with any of the clinico-pathologic characteristics.

\section{Co-expression of p53 and MDM2 proteins (p53/ MDM2):}

Thirty-three out of 45 cases (97.1\%) showed concordant over expression of both p53 and MDM2 proteins. Eleven cases (24.4\%) showed p53-/MDM2+ and $1(2.2 \%)$ was p53+/MDM2-. p53 expression did not show any significant correlation with MDM2 expression $(p$-value $=1.000)$.

\section{Relationship of Ki-67LI with p53, MDM2 and p53/ MDM2 expression:}

The Ki-67 immuno-reactivity was not seen in the one case that was also negative for MDM2 but it was positive for p53. The p53 immuno-negative cases showed higher Ki-67LI (26.12 \pm 24.42$)$ than p53 immuno-positive cases $(22.48 \pm 22.64)$ but this was not statistically significant ( $p$-value $=0.625$; Table 2 ) However, the Ki-67LI showed no significant correlation with p53 immuno-reactivity. Ki-67LI was also not significant associated with MDM2 or p53/MDM2 expression (Table 2).

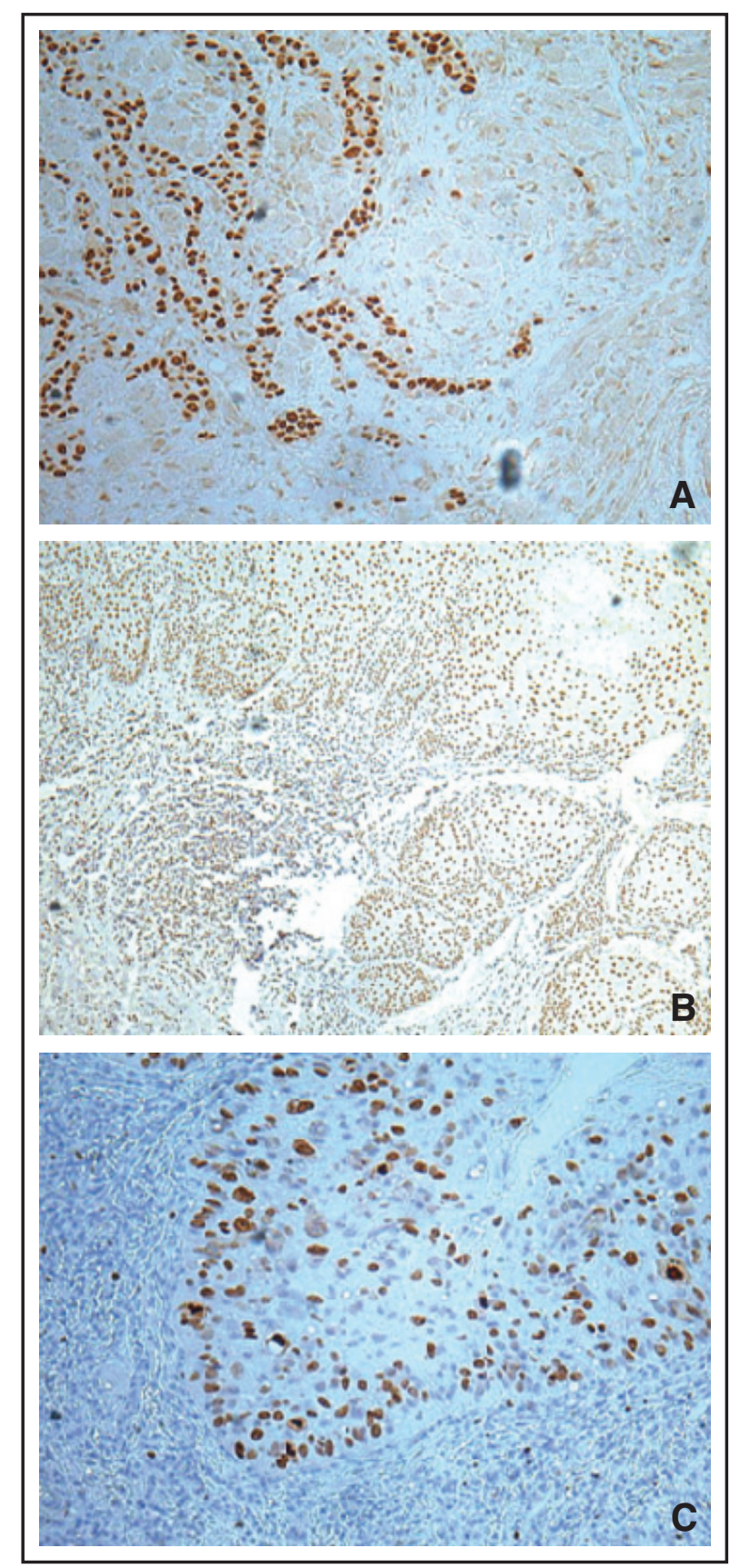

Figure 1. Expression of p53, MDM2 and Ki-67 in OSCC. Photomicrography shows A. Nuclear staining of p53 at the periphery of the tumor island (Original Magnification 100x). B. Nuclear staining of MDM2 protein in all layers of the tumor epithelium (Original Magnification 40x). C. Nuclear staining of $\mathrm{Ki}-67$ protein in the basal and suprabasal layers at the tumor invasive front (Original Magnification 100x).

Table 2. Correlation of $\mathrm{p} 53$ and MDM2 expression with $\mathrm{Ki}-67 \mathrm{LI}$ in OSCC

\begin{tabular}{lccc}
\hline Immunohistochemical phenotype & $\begin{array}{c}\text { Number of OSCC cases } \\
\mathrm{n}(\%)\end{array}$ & $\begin{array}{c}\text { Ki-67LI } \\
\text { (Mean } \pm \text { SD) }\end{array}$ & $p$-value \\
\hline p53 immunopositive cases & $34(75.6)$ & $22.48 \pm 22.64$ & 0.625 \\
p53 immunonegative cases & $11(24.4)$ & $26.12 \pm 24.42$ & $23.90 \pm 22.84$ \\
MDM2 immunopositive cases & $44(97.8)$ & - & 0.268 \\
MDM2 immunonegative cases & $1(2.2)$ & $23.16 \pm 22.64$ & 0.916 \\
Combined p53/MDM2 & $33(73.3)$ & $23.94 \pm 24.47$ \\
\hline
\end{tabular}

Analysis was done using Mann-Whitney test 
Relationship of demographic and clinicopathological parameters and expression of $\mathrm{p53}$, MDM2, Ki-67 and p53/MDM2:

The expression of p53, MDM2 and Ki-67 did not show any correlation with demographic and clinicopathological parameters (Table 3 ). The co-expression of p53 and MDM2 showed significance only with the tumour grading $(p$-value $=0.045)$ whereas the demographic and all other clinico-pathologic parameters were not significant (Table 4).

\section{Systematic search:}

The search in PubMed Medline and Elsevier Science Direct yielded a total of 983 and 3483 articles respectively; of these 935 and 3468 articles were excluded by title/abstract review. After removing duplicated studies from the two search engines; 50 articles remained for full review, of these only 13 articles met the inclusion criteria for our study. We were not able to obtain the full article by Matsumura et al (1996) so only 12 articles were fully reviewed.

Out of the 12 articles reviewed, the number of cases with individual expression of p53 and MDM2 was obtained from all articles (Table 5a) whereas the numbers of cases with and without co-expression of p53/MDM2 were obtained in 9 articles (Table 5b).

\section{DISCUSSION}

The first suggestion that MDM2 is an oncogene came from the genomic cloning of MDM2 that was amplified in rodent cells and the high tumourigenic potential it conferred in nude mice (20). Oliner et al in 1992

Table 3. Relationship of demographic and clinic-pathological characteristics and expression of p53, MDM2, $\mathrm{Ki}-67$ in OSCC case

\begin{tabular}{|c|c|c|c|c|c|c|c|c|c|c|}
\hline \multirow{2}{*}{$\begin{array}{l}\text { Demographic/ } \\
\text { clinicopathological } \\
\text { characteristic }\end{array}$} & \multirow{2}{*}{$\begin{array}{c}\text { Total } \\
(\mathrm{n})\end{array}$} & \multicolumn{9}{|c|}{ Immmunohistochemical expression of markers, $\mathrm{p}$-value } \\
\hline & & $\begin{array}{l}\text { p53+ } \\
\text { n (\%) }\end{array}$ & $\begin{array}{l}\text { p53- } \\
\text { n (\%) }\end{array}$ & $p$-value & $\begin{array}{l}\text { MDM2+ } \\
\text { n (\%) }\end{array}$ & $\begin{array}{l}\text { MDM2- } \\
\text { n (\%) }\end{array}$ & $p$-value & $\begin{array}{l}\mathrm{Ki}-67+ \\
\mathrm{n}(\%)\end{array}$ & $\begin{array}{l}\text { Ki-67- } \\
\text { n (\%) }\end{array}$ & $p$-value \\
\hline \multicolumn{11}{|l|}{ Age } \\
\hline$<59$ years old & 22 & $16(47.1)$ & $6(54.5)$ & $0.666^{a}$ & $22(50.0)$ & $0(0.0)$ & $1.000^{\mathrm{b}}$ & $16(57.1)$ & $6(35.3)$ & $0.155^{\mathrm{a}}$ \\
\hline$\geq 59$ years old & 23 & $18(52.9)$ & $5(45.5)$ & & $22(50.0)$ & $1(0.0)$ & & $12(42.9)$ & $11(64.7)$ & \\
\hline \multicolumn{11}{|l|}{ Sex } \\
\hline Male & 25 & $16(47.1)$ & $9(81.8)$ & $0.079^{b}$ & $25(56.8)$ & $0(0.0)$ & $0.444^{b}$ & $17(60.7)$ & $8(47.1)$ & $0.371^{\mathrm{a}}$ \\
\hline Female & 20 & $18(52.9)$ & $2(18.2)$ & & $19(43.2)$ & $1(100.0)$ & & 11 (39.3) & $9(52.9)$ & \\
\hline \multicolumn{11}{|l|}{ Race } \\
\hline Indian & 31 & $25(73.5)$ & $6(54.5)$ & $0.277^{b}$ & $30(68.2)$ & $1(100.0)$ & $1.000^{b}$ & $20(71.4)$ & $11(64.7)$ & $0.637^{a}$ \\
\hline Non-Indian & 14 & $9(26.5)$ & $5(45.5)$ & & $14(31.8)$ & $0(0.0)$ & & $8(28.6)$ & $6(35.3)$ & \\
\hline \multicolumn{11}{|l|}{ Site } \\
\hline Others & 12 & $27(79.4)$ & $6(54.5)$ & $0.131^{b}$ & $32(72.7)$ & $1(100.0)$ & $1.000^{b}$ & $21(75.0)$ & $12(70.6)$ & $0.743^{b}$ \\
\hline Tongue & 33 & 7 (20.6) & $5(45.5)$ & & $12(27.3)$ & $0(0.0)$ & & $7(25.0)$ & $5(29.4)$ & \\
\hline \multicolumn{11}{|l|}{ Tumor Size } \\
\hline $\mathrm{T} 1$ and $\mathrm{T} 2$ & 16 & $11(40.7)$ & $5(62.5)$ & $0.424^{b}$ & $16(47.1)$ & $0(0.0)$ & $1.000^{b}$ & $9(40.9)$ & $7(53.8)$ & $0.458^{a}$ \\
\hline T3 and T4 & 19 & $16(59.3)$ & $3(37.5)$ & & $18(52.9)$ & $1(100.0)$ & & $13(59.1)$ & $6(46.2)$ & \\
\hline \multicolumn{11}{|l|}{$\begin{array}{l}\text { Lymph node } \\
\text { metastasis }^{c}\end{array}$} \\
\hline No & 15 & $10(37.0)$ & $5(62.5)$ & $0.246^{b}$ & $14(41.2)$ & $1(100.0)$ & $0.429^{b}$ & $9(40.9)$ & $6(46.2)$ & $0.762^{a}$ \\
\hline $\mathrm{N} 1$ and N2 & 20 & $17(63.0)$ & $3(37.5)$ & & $20(58.8)$ & $0(0.0)$ & & $13(59.1)$ & 7 (53.8) & \\
\hline \multicolumn{11}{|l|}{ TNM staging ${ }^{c}$} \\
\hline Stage I and II & 11 & $7(25.9)$ & $4(50.0)$ & $0.226^{b}$ & $11(32.4)$ & $0(0.0)$ & $1.000^{\mathrm{b}}$ & $7(31.8)$ & $4(30.8)$ & $1.000^{\mathrm{b}}$ \\
\hline Stage III and IV & 24 & $20(74.1)$ & $4(50.0)$ & & $23(67.6)$ & $1(100.0)$ & & $15(68.2)$ & $9(69.2)$ & \\
\hline \multicolumn{11}{|l|}{ Broders' grading } \\
\hline Well differentiated & 19 & $12(35.3)$ & $7(63.6)$ & $0.160^{\mathrm{b}}$ & $18(40.9)$ & $1(100.0)$ & $0.422^{b}$ & $11(39.3)$ & $8(47.1)$ & $0.609^{a}$ \\
\hline $\begin{array}{l}\text { Moderately + Poorly } \\
\text { differentiated }\end{array}$ & 26 & $22(64.7)$ & $4(36.4)$ & & $26(59.1)$ & $0(0.0)$ & & $17(60.7)$ & $9(52.9)$ & \\
\hline \multicolumn{11}{|l|}{ Pattern of invasion } \\
\hline Cohesive & 14 & $10(29.4)$ & $4(36.4)$ & $0.717^{b}$ & $14(31.8)$ & $0(0.0)$ & $1.000^{\mathrm{b}}$ & $9(32.1)$ & $5(29.4)$ & $0.848^{a}$ \\
\hline Non-cohesive & 31 & $24(70.6)$ & 7 (63.6) & & $30(68.2)$ & $1(100.0)$ & & 19 (67.9) & $12(70.6)$ & \\
\hline
\end{tabular}


Table 4. Relationship between demographic and clinico-pathological characteristic and co-expression of $\mathrm{p53/MDM2}$ in OSCC

\begin{tabular}{|c|c|c|c|c|}
\hline $\begin{array}{l}\text { Demographic/ clinico-pathological } \\
\text { characteristic }\end{array}$ & Total (n) & \multicolumn{2}{|c|}{ Co-expression of p53 and MDM2 } & $p$-value \\
\hline \multicolumn{5}{|l|}{ Age } \\
\hline$<59$ years old & 22 & $16(48.5)$ & $6(50.0)$ & $0.928^{a}$ \\
\hline$\geq 59$ years old & 23 & $17(51.5)$ & $6(50.0)$ & \\
\hline \multicolumn{5}{|l|}{ Sex } \\
\hline Male & 25 & $16(48.5)$ & $9(75.0)$ & $0.113^{a}$ \\
\hline Female & 20 & $17(51.5)$ & $3(25.0)$ & \\
\hline \multicolumn{5}{|l|}{ Race } \\
\hline Indian & 31 & $24(72.7)$ & 7 (58.3) & $0.470^{\mathrm{b}}$ \\
\hline Non-Indian & 14 & $9(27.3)$ & $5(41.7)$ & \\
\hline \multicolumn{5}{|l|}{ Site } \\
\hline Others & 33 & $26(78.8)$ & 7 (58.3) & $0.254^{b}$ \\
\hline Tongue & 12 & 7 (21.2) & $5(41.7)$ & \\
\hline \multicolumn{5}{|l|}{ Tumor Sizec } \\
\hline $\mathrm{T} 1$ and $\mathrm{T} 2$ & 16 & $11(42.3)$ & $5(55.6)$ & $0.700^{\mathrm{b}}$ \\
\hline T3 and T4 & 19 & $15(57.7)$ & $4(44.4)$ & \\
\hline \multicolumn{5}{|l|}{ Lymph node metastasis ${ }^{c}$} \\
\hline No & 15 & $9(34.6)$ & $6(66.7)$ & $0.129^{b}$ \\
\hline $\mathrm{N} 1$ and N2 & 20 & $17(65.4)$ & $3(33.3)$ & \\
\hline \multicolumn{5}{|l|}{ TNM staging $c$} \\
\hline Stage I and II & 11 & $7(26.9)$ & $4(44.4)$ & $0.416^{b}$ \\
\hline Stage III and IV & 24 & $19(73.1)$ & $5(55.6)$ & \\
\hline \multicolumn{5}{|l|}{ Broders' grading } \\
\hline Well differentiated & 19 & $11(33.3)$ & $8(66.7)$ & $0.045^{a}$ \\
\hline Moderately + Poorly differentiated & 26 & $22(66.7)$ & 4 (33.3) & \\
\hline \multicolumn{5}{|l|}{ Pattern of invasion } \\
\hline Cohesive & 14 & $10(30.3)$ & 4 (33.3) & $1.000^{\mathrm{b}}$ \\
\hline Non-cohesive & 31 & $23(69.7)$ & $8(66.7)$ & \\
\hline
\end{tabular}

aAnalysis was done using chi-square test

${ }^{b}$ Analysis was done using Fisher exact test

cNumbers do not add up to total due to missing data

Table 5a. Over-expression of p53 and MDM2 in all studies reviewed including the present study

\begin{tabular}{|c|c|c|}
\hline Study & $\begin{array}{l}\text { Over-expression of p53 } \\
n(\%)\end{array}$ & $\begin{array}{c}\text { Over-expression of MDM2 } \\
\mathrm{n}(\%)\end{array}$ \\
\hline Stoll et al (1998)(22) & $54 / 107(50.5 \%)$ & 78/107 (72.9\%) \\
\hline Regezi et al (1999)(23) & $42 / 72(58.3 \%)$ & $14 / 71(19.7 \%)$ \\
\hline Agarwal et al (1999)(16) & 45/65 (69.2\%) & $51 / 65(78 \%)$ \\
\hline $\mathrm{Ng}$ et al (1999)(17) & $58 / 84(69 \%)$ & $22 / 84(26.2 \%)$ \\
\hline Partridge et al (1999)(24) & $25 / 45(55.6 \%)$ & $43 / 45(95.6 \%)$ \\
\hline Ralhan et al (2000)(25) & $31 / 46(67.4 \%)$ & $71 / 100(71 \%)$ \\
\hline Li et al $(2000)^{(26)}$ & $29 / 38(76 \%)$ & $19 / 38(50 \%)$ \\
\hline Sano et al (2000)(27) & 13/37 (35.1\%) & 10/37 (27.0\%) \\
\hline Shwe et al (2001) ${ }^{(18)}$ & $30 / 40(75 \%)$ & $29 / 40(72.5)$ \\
\hline Yanamoto et al (2002)(2) & $44 / 69(63.8 \%)$ & $25 / 69$ (36.2\%) \\
\hline Pande et al (2002)(28) & $69 / 105(66 \%)$ & $72 / 105(69 \%)$ \\
\hline Liu et al (2004)(29) & $81 \%$ & $88 \%$ \\
\hline Present study (2011) & $34(75.6 \%)$ & $44(97.8)$ \\
\hline
\end{tabular}


Table 5b. Co-expression of p53 and MDM2 in all studies reviewed including the present study

\begin{tabular}{lccc}
\hline Study & $\begin{array}{c}\text { Co-expression of } \\
\text { p53/MDM2 } \\
\mathrm{n}(\%)\end{array}$ & $\begin{array}{c}\text { Lack of co-expression } \\
\text { of p53/MDM2 } \\
\mathrm{n}(\%)\end{array}$ & $\begin{array}{c}\text { Total number } \\
\text { of cases } \\
\mathrm{n}(\%)\end{array}$ \\
\hline Partridge et al (1999)(24) & $24(53.3)$ & $21(46.7)$ & $45(100.0)$ \\
Agarwal et al $(1999)^{(16)}$ & $39(60.0)$ & $26(40.0)$ & $65(100.0)$ \\
Ng et al (1999)(17) & $17(20.2)$ & $67(79.8)$ & $84(100.0)$ \\
Regezi et al $(1999)^{(23)}$ & $12(16.9)$ & $59(83.1)$ & $71(100.0)$ \\
Ralhan et al $(2000)^{(25)}$ & $24(52.2)$ & $22(47.8)$ & $46(100.0)$ \\
Li et al $(2000)^{(26)}$ & $13(34.2)$ & $25(65.8)$ & $38(100.0)$ \\
Sano et al $(2000)^{(27)}$ & $0(0.0)$ & $37(100)$ & $37(100.0)$ \\
Shwe et al $(2001)^{(18)}$ & $25(62.5)$ & $15(37.5)$ & $40(100.0)$ \\
Yanamoto et al (2002) & $20(29.0)$ & $49(71.0)$ & $69(100.0)$ \\
Present study $(2011)$ & $33(73.3)$ & $12(26.7)$ & $45(100.0)$ \\
\hline
\end{tabular}

mapped the human homologue of MDM2 to chromosome 12q13-14 and also showed it to be amplified in approximately $30 \%$ of soft tissue tumours and osteosarcomas (8). Momand et al (1992) demonstrated that MDM2 is a $90 \mathrm{kDa}$ phospho protein that co-immuno precipitate with p53 and further showed that this inactivates the transactivation activity of the p53 protein, thus elucidating the oncogenic property of MDM2 (9).

In this study, the over-expression of MDM2 was present in all but one case of OSCC $(97.8 \%)$ which is one of the highest when compared to finding from other studies were the reported percentage may range from $19.7 \%$ (24) to $100 \%$ (30). The over-expression of MDM2 has been shown previously to be due to gene amplification, enhanced transcription or translation (25). The MDM2 expression was present in only $26.2 \%$ of cases studied by $\mathrm{Ng}$ et al (1999), and this observation led them to suggest that MDM2 may not be important in oral carcinogenesis which contradicts the findings of Agarwal et al (1999) and Ralhan et al (2000). Notably, Ralhan et al (2000) showed significant correlation between MDM2 protein overexpression and tumour stage and also loss of cell differentiation.

p53 acts as a checkpoint gene. It either blocks cell cycle progression or induces apoptosis in response to DNA damage and stress. During stress there is an increase in the level of p53 protein within 1 to 12 hours (1) which is due to the combination of an increase in p53 translation rate (31) and a decrease in p53 degradation rate (32). In addition, the level of p53 is also governed by MDM2 which binds to p53 directly to initiate p53 degradation (33). In the present study, the over-expression of p53 was seen in only 34 cases $(75.6 \%)$. Most of the studies have shown MDM2 to be over-expressed in more number of cases studied than p53 except $\mathrm{Ng}$ et al (1999), Regezi et al (1999), Li et al (2000), Sano et al (2000) and Yanamoto et al (2002) where p53 was expressed in more number of cases (Table 5a). These discrepancies could be explained by the fact that, factor other than p53 regulates MDM2 (24). Other mechanisms such as chromosomal translocation or mutation could also increase the level of MDM2 protein (34-36).

In this study, the co-expression of p53/MDM2 was found in $73.3 \%$ of OSCC cases. The co-expression of p53 and MDM2 has been reported in a subset of osteosarcomas (15), melanomas (13) and $60 \%$ of OSCCs (16). The co-existence of p53 and MDM2 aberration is indicative of a 'gain of function' phenotype with more aggressive characteristics (16). When compared to other studies of the systematic review the co-expression of $\mathrm{p} 53 / \mathrm{MDM} 2$ in the present study was the highest $(73.3 \%)$. We hypothesed this could be due to the tobacco/betel quid chewing habits which is predominantly practiced by the ethnic Indian in Malaysia since majority of our samples were obtained from patients of Indian ethnicity.

In the present study, there was no statistical difference between the co-expression of p53/MDM2 and their lack of co-expression of p53/MDM2 ( $p$ value $=1.000$ ) (Table 4). This is in contrast to the systematic reviewed studies by Agarwal et al (1999), Shwe et al (2001) and Yanamoto et al (2002) but similar to other studies by $\mathrm{Ng}$ et al (1999), Li et al (2000) and Liu et al (2004) that did not show any significant correlation between the co-expression and the lack of coexpression of $\mathrm{p} 53 / \mathrm{MDM} 2$. These results suggest the existence of a $\mathrm{p} 53$-independent MDM2 regulatory pathway (29) and that these pathways may also be important in OSCC (26). Furthermore, it shows that the functional status of p53 is not the only factor that determines the expression of MDM2 (26). This is further supported by the study of Ralhan et al (2000), where three different isoforms of MDM2 proteins (i.e. p90, p76 and p57) were identified. The p90 and p57 proteins can bind to $\mathrm{p} 53$ protein and cause the accumulation of wild-type p53 in oral cancer. They also detected several alternatively spliced MDM2 transcripts in transformed cell lines/tumours which have lost the ability to bind to p53 proteins as they lack the p53 binding domain and thus are not able to regulate p53 transactivation function. They further 
suggested that isoform p76 of MDM2 may contribute directly to oncogenic potential by alternative p53independent pathways as MDM2 has the ability to activate E2F1/DP1 transcription factors (36) and interact with $\mathrm{Rb}$ protein (37). Notably, in 11 OSCCs $(24.4 \%)$ where over-expression of MDM2 was observed, p53 expression was absent further supporting a p53-independent role for MDM2 in the oral carcinogenesis in these tumours (16).

Interestingly, we found that the co-expression of p53/MDM2 was significantly correlated with tumour differentiation $(p$-value $=0.045)$ (Table 4$)$. This result was similar to Pande et al (2002) and Shwe et al (2001) but in contrast to Yanamoto et al (2002). Pande et al (2002) also reported that the co-expression of $\mathrm{p} 53 /$ MDM2 was significantly related to the nodal involvement. In contrast, in the present study there was no significant association found (Table 4). The tumour differentiation and nodal involvement of tumour are parameters associated with aggressive tumour behavior and therefore the result of Pande et al (2002) suggests that co-expression of $\mathrm{p} 53 / \mathrm{MDM} 2$ could be markers of aggressive tumours. However, our results did not directly support this given that the data indicated significant association with poor tumour differentiation but not with nodal metastasis.

Yanamoto et al (2002) suggested that MDM2 expression and the co-expression of p53/MDM2 were closely related to tumour proliferation. They used Ki-67LI as a marker for cellular proliferation and showed Ki-67LI of co-expression of p53/MDM2 was significantly higher than the lack of co-expression of these proteins. Consistently, 1 case in this series which was MDM2 immune-negative was also immunenegative for Ki-67 expression but positive for p53. However overall, Ki-67LI was not significant associated with MDM2 positive tumours ( $p$ value $=0.268) \quad($ Table 2$) . \mathrm{Ki}-67 \mathrm{LI}$ was also not significantly associated with the co-expression of $\mathrm{p} 53 /$ MDM2 ( $p$-value=0.916) (Table 2). Therefore the correlation suggested by Yanamoto et al (2002) failed to be proven in our study, and this could be due to a limited sample size.

\section{CONCLUSION}

In conclusion, the present study showed that the expression of MDM2 was not significantly associated with p53 expression, suggesting that MDM2 expression is mediated by p53-independent pathways or mutated p53 could not induce the expression of MDM2 in this set of OSCCs. The E2F1/DP1 transcription factors and $\mathrm{Rb}$ protein pathways have to be studied in this set of OSCC. Whereas, the systematic review has clearly shown that both p53-dependent and p53-independent pathways that regulate MDM2 play a role in oral carcinogenesis. The co-expression of $\mathrm{p} 53 /$ MDM2 was not significantly associated with Ki-67LI in the present study, again this need to be confirmed with larger sample size. The only clinico-pathological parameter that correlated significantly with coexpression of $\mathrm{p} 53 / \mathrm{MDM} 2$ is the tumour differentiation which is suggestive of aggressive tumour behavior. The limitation of this study was that it did not take into account patient survival and disease recurrence; these factors could have been examined to determine the prognostic significance of co-expression of $\mathrm{p} 53 /$ MDM2, however given the lack of correlation between the co-expression of p53/MDM2 with existing clinicopathological parameters, in particular lymph node metastasis, we think that the prognostic role for these markers would be minimal.

\section{ACKNOWLEDGMENT}

The authors would like to record the appreciation to Mr. Vincent-Chong Vui King for providing several full articles used for the systematic review of this study.

\section{REFERENCES}

1. Omar ZA, Ali ZM, Tamin NSI. Malaysian Cancer Statistics - Data And Figure: Peninsular Malaysia 2006. National Cancer Registry, Ministry of Health Malaysia 2006.

2. Yanamoto S, Kawasaki G, Yoshitomi, et al. p53, MDM2, and p21 expression in oral squamous cell carcinoma: Relationship with clinicopathologic factors. Oral Surgery Oral Med Oral Pathol. 2002; 94: 593-600.

3. Kastan MB, Onyekwere O, Sidransky D, et al. Participation of p53 protein in the cellular response to DNA damage. Cancer Res. 1991; 51: 6304-11.

4. Sittel C, Ruiz S, Volling P, et al. Prognostic significance of Ki-67 (MIB1), PCNA and p53 in cancer of oropharynx and oral cavity. Oral Oncol. 1999; 35: 583-9.

5. Barak Y, Juven T, Haffner R, et al. MDM2 expression is induced by wild type p53 activity. EMBO J 1993; 12: 461-8.

6. Wu X, Bayle JH, Olson D, et al. The p53-MDM-2 autoregulatory feedback loop. Genes Dev. 1993; 7: 1126-36.

7. Chen CY, Oliner JD, Zhan Q, et al. Interaction between p53 and MDM2 in a mammalian cell cycle checkpoint pathway. Proc Natl Acad Sci USA. 1994; 91: 2684-8. 
8. Oliner JD Kinzler KW, Meltzer PS, et al. Amplification of gene encoding a p53-associated protein in human sarcomas. Nature 1992; 358: 80-3.

9. Mohamed J, Zambetti GP, Olson DC, et al. The MDM2 oncogene product forms a complex with p53 protein and inhibits p53 mediated transactivation. Cell 1992; 69: 1237-45.

10. Chen J, Wu X, Lin J, et al. MDM-2 inhibits the G1 arrest and apoptosis function of the p53 tumor suppressor protein. Mol Cell Biol. 1996; 16: 2445 52.

11. Haupt Y, Barak Y and Oren M. Cell type-specific inhibition of p53-mediated apoptosis by MDM2. EMBO J 1996; 15: 1596-606.

12. Lundgern K, Montes de Oca Luna R, McNeill YB, et al. Targeted expression of MDM2 uncouples $\mathrm{S}$ phase from mitosis and inhibits mammary gland development independent of p53. Genes Dev. 1997; 11: 714-25.

13. Gelsleichter L, Gown AW, Zarro RJ et al. p53 and MDM2 expression in malignant melanoma: an immunocytochemical study of expression of $\mathrm{p} 53$, MDM2, and markers of cell proliferation in primary versus metastatic tumours. Mod Pathol. 1995; 8: 530-5.

14. Schmitz-Drager BJ, Kushima M, Goebell P, et al. p53 and MDM2 in the development and progression of bladder cancer. Eur Urol. 1997; 32: 487-493.

15. Cordon-Cardo C, Laters E, Drobhjak MR, et al. Molecular abnormalities of MDM2 and $p 53$ genes in adult soft tissue sarcomas. Cancer Res. 1994; 54: 794-9.

16. Agarwal S, Mathur M, Srivastava A, et al. MDM2/ p53 co-expression in oral premalignant and malignant lesions: potential prognostic implications. Oral Oncol. 1999; 35: 209-16.

17. $\mathrm{Ng}$ IOL, Lam KY, $\mathrm{Ng} \mathrm{M}$, et al. Expression of p21/ waf1 in oral squamous cell carcinoma-correlation with p53 and MDM2 and cellular proliferation index. Oral Oncol. 1999; 35: 63-9

18. Shwe M, Chiguchi G, Yamada S et al. p53 and MDM2 co-expression in tobacco and betel chewing-associated oral squamous cell carcinomas. J Med Dent Sci. 2001; 48: 113-9.
19. Sasaki K, Murakami T, Kawasaki M, et al. The cell cycle associated change of the $\mathrm{Ki}-67$ reactive nuclear antigen expression. J Cell Physiol. 1987; 133: $579-84$.

20. Fakharzadeh SS, Trusko SP and George DL. Tumorigenic potential associated with enhanced expression of a gene that is amplified in a mouse tumor cell line. EMBO J 1991; 10: 1565-9.

21. Matsumura T, Yoshihama Y, Kimura T, et al. p53 and MDM2 expression in oral squamous cell carcinoma. Oncology 1996; 53: 308-12.

22. Stoll C, Baretton G and Löhrs U. The influence of p53 and associated factors on the outcome of patients with oral squamous cell carcinoma. Virchows Arch. 1998; 433: 427-33.

23. Regezi JA, Dekker NP, McMillan A, et al. p53, p21, $\mathrm{Rb}$, and MDM2 proteins in tongue carcinoma from patients $<35$ versus $>75$ years. Oral Oncol. 1999; 35: $379-83$.

24. Partridge M, Kiguwa S, Emilion G, et al. New insight into p53 stabilisation in oral squamous cell carcinoma. Oral Oncol. 1999; 33: 45-55.

25. Ralhan R, Agarwal S, Mathur M, et al. Induction of MDM2-P2 transcript correlates with stabilized wild-type p53 in betel- and tobacco-related human oral cancer. Amer J Pathol. 2000; 157: 58796.

26. Li X-J, Murai M, Koyama T, et al. MDM2 over expression with alteration of the $\mathrm{p} 53$ protein and gene status in oral carcinogenesis. Jpn J Cancer Res. 2000; 91: 492-8.

27. Sano T, Hikino $T$, Xue Q, et al. Immunohistochemical inactivation of p14ARF concomitant with MDM2 over expression inversely correlates with p53 over expression in oral squamous cell carcinoma. Pathol Int. 2000; 50: 709-716.

28. Pande P, Soni S, Kaur J et al. Prognostic factors in betel and tobacco related oral cancer. Oral Oncol. 2002; 38: 491-9.

29. Liu C-J, Chang K-W, Chao S-Y, et al. The molecular markers for prognostic evaluation of areca-associated buccal squamous cell carcinoma. J Oral Pathol Med. 2004; 33: 327-34. 
30. Lim KP, Sharifah H, Lau SH et al. Alterations of the p14ARF-p53-MDM2 pathway in oral squamous cell carcinoma: MDM2 overexpression is a common event. Oncol Rep. 2005; 14 (4): 963968 .

31. Fu L, Minden MD, Benchimol S, et al. Translational regulation of human p53 gene expression. EMBO J 1996; 15: 4392-401.

32. Maltzman W and Czyzyk L. UV irradiation stimulates levels of p53 cellular tumor antigen in nontransformed mouse cell. Mol Cell Biol. 1984; 4: 1689-94.

33. Haupt Y, Maya R, Kazaz A, et al. MDM2 promotes the rapid degradation of p53. Nature 1997; 387 : 296-9.
34. Qian W, Hu LF, Chen F, et al. Infrequent MDM2 gene amplification and absence of gross WAF1 gene alterations in nasopharyngeal carcinoma. Eur J Cancer B Oral Oncol. 1995; 31B: 328-32.

35. Marchetti A, Buttitta F, Girlando S, et al. MDM2 gene alterations and MDM2 protein expression in breast carcinomas. J Pathol. 1995; 175: 31-8.

36. Martin K, Trouche D, Hagemeier C, et al. Stimulation of E2F1/DP1 transcriptional activity by MDM2 oncoprotein. Nature 1995; 375: 6914.

37. Xiao ZX, Chen J, Levine AJ, et al. Interaction between the retinoblastoma protein and the oncoprotein MDM2. Nature 1995; 375: 694-8. 